\title{
Struggle for a Meaningful Life after Obesity Treatment-A Qualitative Systematic Literature Review
}

\author{
Kristine Rørtveit ${ }^{1,2 *}$, Bodil Furnes ${ }^{2}$, Elin Dysvik ${ }^{2}$, Venke Ueland ${ }^{2}$ \\ ${ }^{1}$ Researcher of Psychiatric Nursing at the Stavanger University Hospital, Stavanger, Norway \\ ${ }^{2}$ Faculty of Health Sciences University of Stavanger, Stavanger, Norway \\ Email: *kristine.rortveit@sus.no
}

How to cite this paper: Rørtveit, K., Furnes, B., Dysvik, E. and Ueland, V. (2017) Struggle for a Meaningful Life after Obesity Treatment-A Qualitative Systematic Literature Review. Open Journal of Nursing, 7, 1474-1492.

https://doi.org/10.4236/ojn.2017.712103

Received: October 26, 2017

Accepted: December 25, 2017

Published: December 28, 2017

Copyright $\odot 2017$ by authors and Scientific Research Publishing Inc. This work is licensed under the Creative Commons Attribution International License (CC BY 4.0).

http://creativecommons.org/licenses/by/4.0/

\begin{abstract}
Aim: The aim of this review was to describe and systemize existing literature on patient-experiences in the context of obesity treatment. The review question was: How do patients describe their experiences after obesity treatment? Background: Obesity problems vary on a continuum of intensity and types of problems during different periods of life. An increasing amount of available treatment requires patients and professionals to make choices concerning the suitability of the individual patient to undergo certain types of treatment. Surgical treatment is considered sustainable and more successful for weight loss than other interventions. Alternatively, conservative treatment of obesity may be a matter of dealing with mental issues as well as diet and exercise. In a qualitative context, a deeper understanding related to patients' own posttreatment experiences is needed. Methods: A systematic qualitative literature review was conducted for the period from 2006 to November 2016. The search was done in Medline, Embase and CINAHL using the words: Obesity, binge eating, patient, experience or perspective, treat or therap or surgery or cognitive, intervention, programme. Results and discussion: 15 studies were included and an overview of the qualitative designs was presented. From the content analysis, one main theme, Struggle for a meaningful life during transition related to obesity treatment, was developed. The main theme was derived from three themes related to the patients' challenges when searching for positive self-existence, for relevant treatment-support, and for a balance to obtain inner and outer control. Clinical implications: Different types of obesity treatment create processes of transitions. However, it is crucial that clinicians are aware of the potential existential struggle after obesity treatment that is experienced by the individual patients. Clearly, some patients need interventions targeting mental challenges at different levels. Future interventions should take into account that physical and mental treatment must work together.
\end{abstract}




\section{Keywords}

Obesity Treatment, Patient Experiences, Qualitative Review

\section{Struggle for a Meaningful Life after Obesity Treatment-A Systematic Qualitative Literature Review}

Patients who seek treatment for obesity report different problems and levels of intensity during different periods of life. Treatment-intensive obesity is associated with an increased prevalence of several physical and mental conditions [1]-[7]. Experiences after obesity treatment are identified and described in the literature, such as fear of being fat, losing control, mood, behaviour and psychological changes; depression and isolation and becoming preoccupied with thoughts about food [8]. A qualitative study on obese peoples' experiences reports a lack of emotional self-care and a desire to decrease emotional eating [9]. The process of transition when participating in a weight loss programme was reported to be complex, as the participants described several dimensions and phases [10].

The increasing amount of available treatment requires patients and professionals to make choices about the suitability to undergo certain types of treatment of the individual patient [11]. As early as 1976, gastric bypass was documented as effective for weight loss in obese patients [12]. Later, surgical interventions' have proven to be sustainable and successful resulting in weight loss and various health benefits [13] [14] [15] [16] [17].

Failure to lose weight after surgical interventions is also reported and often discussed in conjunction with surgery methods [18] [19]. Moreover, a Brazilian review concluded that it is important to assess personality characteristics before surgery in order to estimate prognosis and develop interventions for the population [20]. Another study concluded that clinical treatment of obesity may be a matter of dealing with mental issues such as shame and social isolation more than a matter of diet and exercise [21]. A qualitative Canadian study suggested that weight stigma and weight bias should be addressed and that positive mental well-being should be promoted when tailoring support to individuals living with obesity [22]. A Dutch study suggested that future studies on unsuccessful weight-loss outcomes should examine how a focus on binge eating management and external and emotional eating might improve the outcome [23]. Cognitive behavioural therapy (CBT) is one of the preferred methods targeting the pattern and maintenance of binge eating [24]. It was found that healthcare workers had more focus on physical ailments, that they were judgmental about weight and were unable to distinguish binge eating disorder from obesity. The desire for safe and non-judgmental interactions with the healthcare workers was highlighted [25]. A study on very low calorie diet found that such diet and group interventions was feasible in primary healthcare and maintained weight loss even after one year [26]. 
Changes in health and illness of individuals, such as is the case in obesity, create a process of transition, and these patients in transition tend to be more vulnerable to risk that can potentially affect their health [27]. Transition in this context is a term referring to the movement from one state, condition and place to another. In order to tailor specific interventions for these patients, there is a need for developing a deeper understanding of obesity treatment and the patients' experiences during transition. In this review, we seek to highlight the intersection in treatment of obesity and eating problems related to obesity, focusing on the patient experiences and using suitable criteria to assess and summarize evidence. The review also seeks to find out how existing literature describes patients' own experiences in the context of treatment; this may make an important qualitative contribution to support the interventions and follow-up offered to individuals with obesity.

\section{Aim and Review Question}

The aim of this review was to describe and systemize existing literature on patient experiences in the context of obesity treatment. The review question was: How do patients describe their experiences after obesity treatment?

\section{Methods}

This is an explorative and descriptive design [28] using a qualitative systematic review [29]. The perspective of the review was the patient view on how treatment was provided [30] [31]. Qualitative studies on treatment related to obesity based on interviews with patients were systematically identified, thoroughly read and analysed [29] [30] [31] [32] [33] to expand knowledge about patients' experiences with obesity treatment. The review will provide implications for a future study-protocol. The review will also provide implications for nursing and patient education as well as a group treatment intervention.

The systematic literature review involves the identification, selection, analysis and description of existing knowledge, using procedures that make the review process disciplined and transparent [28] [34]. The review was performed to ascertain the status of knowledge in published research during the past 10 years. The authors were four nurse researchers working in a university and a university hospital on the West coast of Norway.

\subsection{Search Strategy and Search Words}

A search was performed in the Medline (75), Embase (413) and CINAHL (45) databases covering the period January 2006 to December 2016. The search words were obesity AND binge eating AND patient ${ }^{\star}$ AND experience* OR perspective $^{\star}$ AND treat ${ }^{\star}$ or therap* ${ }^{\star}$ or surgery or cognitive* AND intervention AND programme. One expert from the university hospital library was hired to design the search strategies. Reference lists of the selected papers were screened and an individual search was performed. 
A total of 533 abstracts were included in the first hit (please see Appendix I). A digital and manual qualitative method filter was employed. During the search, the authors read the abstracts, and from all the databases, 15 met the inclusion criteria. We structured the themes as in a thematic analysis [29] [35]. Categories and sub-categories were formulated according to the aim of the study.

\subsection{Study Selection}

According to the inclusion criteria, only qualitative studies focusing on patients' experiences from in-depth interviews after obesity-treatment were included. The studies were published in peer reviewed English language journals. The inclusion criteria were qualitative studies; on the patients' perspective of the experiences of obesity treatment, published in English language journals, published during the past ten years. Reports, editorials, textbooks, unpublished dissertations, quantitative studies, studies on professionals other than nurses, peer experiences and in which patient experiences were not the focus were excluded. According to the review question and inclusion criterion, the four researchers agreed on selecting the 15 papers to read in full.

\subsection{Assessment of Methodological Quality}

The methodological quality was assessed according to the Critical Appraisal Skills Program. In this phase the included papers were assessed and rated due to methodological checklist of key criteria relevant to qualitative studies [36]. The four authors (KR/BF, ED, VU) independently assessed the quality of the studies and reached an agreement by re-reading and discussing the studies. Together they reached a final decision (presented in Appendix II).

\subsection{Content Analysis}

A thematic, data-driven qualitative content analysis based on Graneheim and Lundman (2004) was performed in steps and summarized, and the findings were abstracted. In the first step, categories from each study's findings were identified. The included studies were red several times by the four authors, and in the content analysis we payed specially attention to the findings and discussions in the included studies. We looked for structures and variations and from the rich and variated data both similarities and diversities were illuminated and categorised. Thereafter, the categories were organized, sorted and summarized in themes. Finally the descriptive themes evolved by reflecting, labelling and comparing them according to the review question [29] [35]. Experiences of obesity treatment were reflected on, discussed and analysed in accordance with the review question.

\section{Results}

15 studies were identified and red according to the aim of the study (Table 1, overview of included articles). 
Table 1. Overview of the included studies.

\begin{tabular}{|c|c|c|c|c|c|c|}
\hline No/Year & Author & Title & Aim & $\begin{array}{c}\text { Qualitative } \\
\text { methods/design }\end{array}$ & $\mathrm{N}$ & Intervention \\
\hline 1) 2014 & $\begin{array}{l}\text { A. A. Geraci, } \\
\text { A. R. Brunt, } \\
\text { M. A. Marihart, [37] }\end{array}$ & $\begin{array}{l}\text { Social support systems: } \\
\text { A qualitative analysis } \\
\text { of female bariatric } \\
\text { patients after the first } \\
\text { two years postoperative }\end{array}$ & $\begin{array}{l}\text { To explore experiences } \\
\text { of patients who have } \\
\text { undergone bariatric surgery } \\
\text { at least two years prior and to } \\
\text { gain an understanding of the } \\
\text { successes and challenges } \\
\text { they have faced since surgery. }\end{array}$ & $\begin{array}{l}\text { Phenomenological } \\
\text { approach. } \\
\text { Semi-structured } \\
\text { interviews. }\end{array}$ & 9 & Surgery \\
\hline 2) 2014 & $\begin{array}{l}\text { E. Natvik, } \\
\text { E. Gjengedal, } \\
\text { C. Moltu, } \\
\text { M. Råheim, [38] }\end{array}$ & $\begin{array}{l}\text { Re-embodying eating: } \\
\text { patients' experiences } \\
\text { five years after } \\
\text { bariatric surgery }\end{array}$ & $\begin{array}{l}\text { To contribute to the } \\
\text { development of clinical } \\
\text { practice. Explored meanings } \\
\text { attached to eating in the long } \\
\text { term and sought descriptions } \\
\text { of change and bodily sensations. }\end{array}$ & Interviews & 14 & Surgery \\
\hline 3) 2014 & $\begin{array}{l}\text { M. Wiklund, } \\
\text { F. M. Olbers, } \\
\text { C. Willén, [45] }\end{array}$ & $\begin{array}{l}\text { Experiences of Physical } \\
\text { Activity One Year after } \\
\text { Bariatric Surgery }\end{array}$ & $\begin{array}{l}\text { To describe how patient } \\
\text { experience physical activity } \\
\text { one year after bariatric surgery. }\end{array}$ & Interviews & 24 & $\begin{array}{l}\text { Physical } \\
\text { activity after } \\
\text { bariatric } \\
\text { surgery }\end{array}$ \\
\hline 4) 2013 & $\begin{array}{l}\text { S. S. da Silva, } \\
\text { C. Maia Âda, [46] }\end{array}$ & $\begin{array}{l}\text { Patients' experiences } \\
\text { after bariatric surgery: } \\
\text { a qualitative study } \\
\text { at } 12 \text {-month follow-up }\end{array}$ & $\begin{array}{l}\text { To understand patients' } \\
\text { experiences in post-surgery } \\
\text { adaptation related to } \\
\text { bariatric surgery, } 12 \text { months } \\
\text { after this procedure. }\end{array}$ & $\begin{array}{l}\text { Individual } \\
\text { interviews, } \\
\text { grounded } \\
\text { theory } \\
\text { methodology }\end{array}$ & 30 & Surgery \\
\hline 5) 2013 & $\begin{array}{l}\text { E. Natvik, } \\
\text { E. Gjengedal, } \\
\text { M. Råheim, [47] }\end{array}$ & $\begin{array}{l}\text { Totally changed, yet still } \\
\text { the same: patients' lived } \\
\text { experiences five years } \\
\text { beyond bariatric surgery }\end{array}$ & $\begin{array}{l}\text { To describe the essential } \\
\text { meaning of bariatric surgery } \\
\text { patients' long-term experiences } \\
\text { by using a phenomenological } \\
\text { lifeworld approach. }\end{array}$ & Interviews & 8 & Surgery \\
\hline 6) 2012 & $\begin{array}{l}\text { A. F. Klassen, } \\
\text { S. J. Cano, } \\
\text { A. Scott, } \\
\text { Johnson, J. } \\
\text { A. L. Pusic, [51] }\end{array}$ & $\begin{array}{l}\text { Satisfaction and } \\
\text { quality-of-life issues } \\
\text { in body contouring } \\
\text { surgery patients: } \\
\text { a qualitative study }\end{array}$ & $\begin{array}{l}\text { To identify the health and } \\
\text { aesthetic concern from } \\
\text { the patient's perspective. }\end{array}$ & Interviews & 43 & $\begin{array}{l}\text { Body } \\
\text { contouring } \\
\text { after } \\
\text { bariatric } \\
\text { surgery }\end{array}$ \\
\hline 7) 2011 & Drew, P. [50] & $\begin{array}{l}\text { "But then I learned...": } \\
\text { weight loss surgery } \\
\text { patients negotiate } \\
\text { surgery discourses }\end{array}$ & $\begin{array}{l}\text { To examine how patients } \\
\text { negotiate widespread weight } \\
\text { loss surgery discourses. }\end{array}$ & Multi-method & $\begin{array}{l}44 \\
+ \\
55\end{array}$ & Surgery \\
\hline 8) 2011 & $\begin{array}{l}\text { J. Ogden, } \\
\text { S. Avenell, } \\
\text { G. Ellis, [39] }\end{array}$ & $\begin{array}{l}\text { Negotiating control: } \\
\text { patients' experiences } \\
\text { of unsuccessful } \\
\text { weight-loss surgery }\end{array}$ & $\begin{array}{l}\text { To explore experiences } \\
\text { of weight loss surgery that } \\
\text { was deemed unsuccessful. }\end{array}$ & Interviews & 10 & Surgery \\
\hline 9) 2011 & $\begin{array}{l}\text { A. L. Östberg, } \\
\text { I. Wikstrand, } \\
\text { K. Bengtsson } \\
\text { Boström, [40] }\end{array}$ & $\begin{array}{l}\text { Group treatment of obesity } \\
\text { in primary care practice: } \\
\text { a qualitative study of } \\
\text { patients' perspectives }\end{array}$ & $\begin{array}{l}\text { To explore patients' experiences } \\
\text { of very low calorie diet and } \\
\text { subsequent corset treatment of } \\
\text { obesity in a primary care setting. } \\
\text { To explore their perceptions of } \\
\text { factors influencing weight control. }\end{array}$ & $\begin{array}{l}\text { Focus groups and } \\
\text { Grounded Theory }\end{array}$ & & $\begin{array}{l}\text { Very low } \\
\text { calorie diet }\end{array}$ \\
\hline 10) 2010 & $\begin{array}{l}\text { A. Psarou, } \\
\text { I. Brown, [49] }\end{array}$ & $\begin{array}{l}\text { Patients' experiences of } \\
\text { prescribed anti-obesity } \\
\text { drugs and perceptions } \\
\text { of support from primary } \\
\text { care: a qualitative study }\end{array}$ & $\begin{array}{l}\text { To explore the views and } \\
\text { experiences of obese patients } \\
\text { prescribed anti-obesity drugs } \\
\text { in primary care, including } \\
\text { their understanding of guidance } \\
\text { about lifestyle changes. }\end{array}$ & $\begin{array}{l}\text { Semi-structured } \\
\text { interviews }\end{array}$ & 31 & $\begin{array}{l}\text { Anti-obesity } \\
\text { drugs }\end{array}$ \\
\hline
\end{tabular}




\section{Continued}

11) 2010 C. T. LePage, [41

2) 2010 K. Malterud, K. Ulriksen, [42]

S. Visram,

13) 2009 A. Crosland,

H. Cording, [43]

J. Ogden,

14) 2006 C. Clementi, S. Aylwin, [44]

15) 2006 J. Ogden, S. Sidhu, [48]
The Lived Experience of Individuals following

Roux-en-Y Gastric

Bypass Surgery:

A Phenomenological Study

Obesity in general practice:

a focus group study

on patient experiences

Triggers for weight

gain and loss among

participants

in a primary

care-based intervention

The impact of obesity

surgery and the paradox

of control: A qualitative study

Adherence, behavior change,

and visualization: a qualitative

study of the experiences of

taking an obesity medication
To explore the lived

experience the individual

following gastric

bypass surgery.

To explore obese patients'

experiences with GPs'

management of their

weight problems.

To explore beliefs about weight gain, motivation for weight loss and factors contributing to weight maintenance among patients of a primary care-based weight management program.

To explore patients'

experiences of having

obesity surgery.

To examine patients'

experiences of taking orlistat

as a means to explore

adherence and behavior change.
Phenomenological

philosophical me- 12 Surgery

thod

Focus-group

13

GPs

management

Explorative

qualitative design

and semi-structured

interviews

Weight

20 management

intervention

Interviews

15 Surgery

Interviews

Anti-obesity

drugs

First, the quality check was performed according to the critical appraisal skills program [36], (please see Appendix II) and the design and evidence were thoroughly examined. After reviewing the different designs, a qualitative content analysis of each study's findings was performed and revealed one main theme: struggle for a meaningful life during transition related to obesity treatment. This theme described three sub-themes which highlighted the experienced challenges related to three domains in the informants' lives: the self-existence, the treatment-support and the inner and outer control (Table 2).

\subsection{The Qualitative Evidence of Patients' Experiences of Obesity Treatment}

Different aims of the studies pointed to a variety of research approaches. They aimed to explore experiences of patients [37]-[44] in different contexts of obesity treatment: for instance their lived experiences [41] or meaningful experiences post-surgery [37]; their opinions about eating in the long term [38]; or weight loss surgery that was deemed unsuccessful [39]. Experiences of very low calorie diet and subsequent corset treatment of obesity and patients' perceptions of factors influencing weight control were explored [40]; participants' perceptions of GPs ' management of their weight problems [42]; their beliefs about weight gain, motivation for weight loss and factors contributing to weight maintenance of a weight management programme [43] were also examined. The included studies also aimed to contribute to the development of clinical practice by exploring opinions associated with eating in the long term and seeking descriptions of 
Table 2. Overview of the content analysis.

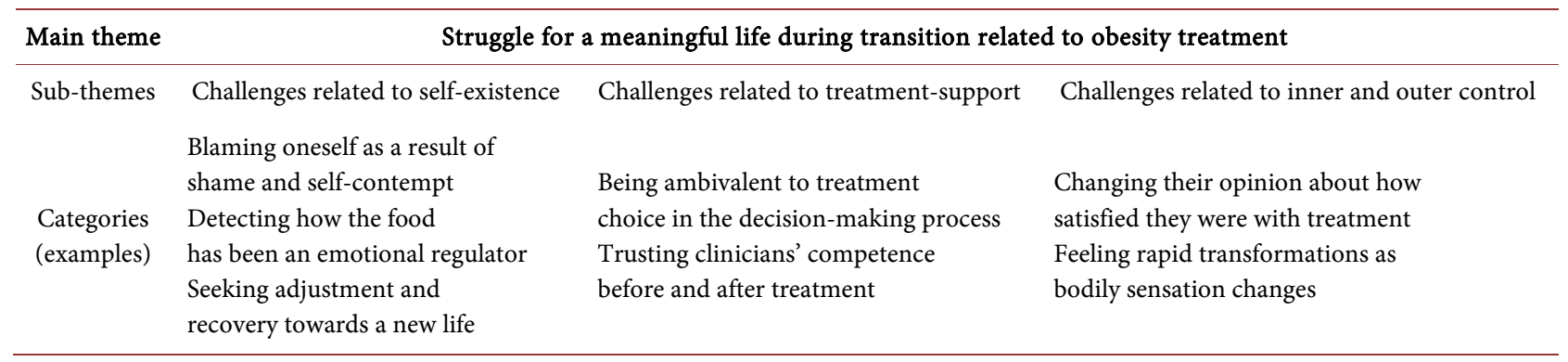

change and bodily sensations [38]; to describe experiences of physical activity after bariatric surgery [45]; and to understand experiences in post-surgery adaptation related to post-bariatric surgery [46]. One study aimed to increase knowledge about the group and their needs during follow-up, and to describe the essential meaning of bariatric surgery patients' long-term experiences [47]. Others aimed to examine experiences of taking obesity medication [48] and anti-obesity drugs combining support from primary care and guidance about life style changes [49]; to examine how patients negotiate widespread weight loss surgery discourses [50]; and to identify the health and aesthetic concern [51].

Seven different treatment methods emerged from the results: bariatric surgery [37] [38] [39] [41] [44] [45] [46] [47] [50] [51] physical activity [45], anti-obesity drugs [48] [49], body countouring [51], group treatment and very low calorie diet [40], GP's management [42], and primary care based weight management [43].

Different designs were applied and described in different terms. One multi-method study [50], qualitative design [49] and an explorative qualitative research design [43] were described. Three phenomenological approaches were included [37] [41] [47]; one investigated and described meaning and essences [37]. Three semi-structured interviews [37] [43] [49] and interview studies from one to ten years after bariatric interventions were revealed [37] [38] [39] [44] [45] [47] [48]. One study interviewed participants who felt that it had failed, where seven of them had had a further successful procedure [39]. Two conducted an individual interview analysis according to grounded theory methodology [40] [46]. Focus group sessions were conducted: In one, five sessions were held focusing on the informants' perceptions of the treatment and experiences of living with obesity [40]; and one held two sessions in a study with a purposive sample related to BMI, where the participants reflected on their health care experiences from general practice [42].

\subsection{Struggle for a Meaningful Life during Transition Related to Obesity Treatment}

The great variety experienced realities among those who had undergone different types of obesity treatment led to one main theme. The main theme Struggle for a meaningful life after obesity treatment was developed and described by 
three subthemes that we interpreted as an expression of struggle at different levels: self-existence, support from others and search for a balance to obtain inner and outer control. The themes will be presented and followed by a discussion.

\subsubsection{Challenges Related to Self-Existence}

The first theme highlighted the inner pressure of uncertainty and emotional regulation when trying to achieve a feeling of self-existence. The self-existence seemed to be an explicit issue pointing to the importance of patients' self-control and its relation to empowerment of the patient choice [44]. The weight loss had an impact on different aspects such as health status, self-esteem and social relationships [44].

Patients had to adapt their own identity in the process of weight reduction to accommodate living with obesity, reducing weight and developing self-management [40]. Surgery challenged the patients by confronting them with a self-image in rapid transformation [41]. A revealed meaning of hope for an improved future related to the surgery was highlighted; for instance, the prevention of an untimely death or proof of overcoming infertility [41]. Difficulty in finding balance between the pros and cons related to surgery was revealed: improvements in daily life were offset by setbacks such as divorce or other losses after surgery [41].

The surgery's impact on daily eating behaviour and the participants' relationship with food was described [44]. Participants discovered how food had filled the void before surgery; a sense of emptiness was awakened [41]. The transformation of self-image was related to a feeling of pride resulting from weight loss. As the change ended and became routine, the feeling of being merely a fat person masquerading in tiny dresses arose [41].

\subsubsection{Challenges Related to Treatment Support}

The second theme highlighted variations in help provided, further therapy and the need for support. This theme was manifested in support and need for support [45]. The importance of patients' personal experiences with weight loss surgery, the personal interactions and education in shaping responses to stigma were highlighted [50]. Experiences in terms of the personal weight histories showed different factors leading to onset of the obesity, failed attempts at weight control and weight cycles [44]. The decision-making process related to surgery involved general motivations, worries and health-specific triggers [44]. Health concerns [43] [49], factors of image and previous experiences of stigmatization were triggers that led to seeking help with weight loss [43]. Ways of sensing one's own body when eating had to be changed due surgical restrictions, and still the patients felt uncertainty about maintaining long-term weight loss [38]. Eating after surgery was described as an ambiguous and sensitive matter of existential and embodied practice [38].

Paradoxes after surgery were discussed [41]. One study described how the second successful surgery led to changes in eating and cognitions because the 
mind had been put in gear after the two procedures [39]. Regained weight after surgery was explained by either the operation mechanics or emotional regulation of eating; and the mind was reported to be neglected after surgery [39]. When surgery was successful, the restricted stomachs were credited and the surgery was viewed as a tool to used [39]. The weight loss and improved physical function after surgery was not reported as synonymous with improved health-related habits and practices in the long term [47].

Different support systems were family, friends, workplace and groups related to surgery [37]. One study highlighted that no common standard is established for bariatric support to follow, and therefore support groups are not equal [37]. Facilitators of successful management of weight were related to personalized messages and support from both peers and professionals [43]. One study reported that support groups were encouraged by the healthcare settings, but only $50 \%$ of the patients reported that they attended them regularly [37].

Experiences after non-surgical interventions were revealed. One study perceived very low calorie diet positively and a corset treatment intervention as less valuable and reflected on how the obese individual struggled to handle demands in their life situation and to recognize their own resources [40]. Implications for understanding behaviour change and adherence in a study on obesity drugs was related to the informants' beliefs about the causes of the obesity, the motivation for taking obesity drugs, and visual side effects [38]. The patients' ambivalence about the obesity drugs was revealed and described expectations that varied from being sceptical to optimistic [49]. The patients wanted their GPs to put obesity on the agenda; insufficient attention to the problem could lead to neglect of their obesity [42]. The patients explained that reluctant on the part of the patient may be a sign of embarrassment rather than rejection [42]. Insufficient enthusiasm and knowledge about treatment on the part of the GP delegated the responsibility to the patient to be informed about available referral resources [42]. The patients needed to be followed up by a GP with considerate attitudes and well-intended advice if they are to experience the follow-up as helpful or as a reinforcement of vulnerable feelings of failure [42]. The same study highlighted that degrading attitudes towards the obesity were perceived as especially subversive by the patient when they came from doctors [42].

Plastic surgery to remove excess skin resulted in several improvements: enhanced physical, psychological, social health, well-being and sexual health concerns [51]. With regard to physical activity, patients experienced both achievements and obstacles one year after surgery [45]. The need for lifestyle change appeared to be high [49]. Patients described an increased understanding of the benefits of physical activities, but it seemed like the need for support appeared necessary [45].

The experiences in taking anti-obesity drugs varied and changed due to different aspects of the treatment: the weight-loss experiences, the side effects and the quality of support [49]. Even though most of the informants were unaware of different types of support, some ways by which the information could be im- 
proved were described as well as the choice and support provided by the primary care [49].

\subsubsection{Challenges to Obtain Inner and Outer Control}

The third theme revealed how participants described the search for balance as a manifestation of control. Issues of control related to the success or failure of weight-loss treatment were described. Patients switched between self-blame and sense of responsibility. This led to inner conflicts between a separated or united mind [39]. One study discussed how surgery may result in a renewed sense of control as it imposes control and limits choices [44]. If surgery failed, it was characterized as a battle of control [39]. Descriptions of belonging to one of two opposite and separate groups were revealed in relation to treatment and outcome: the groups of failure or success [46]. Descriptions of living with tension, ambivalence and reinforced attention related to the body were revealed as the patients expressed demands of control over the body after surgery [47]. Treatment integrated lifestyle changes and highlighted personal commitment as crucial to achieve the objectives [46].

The realization of the importance of food for emotional comfort or easing of problems was revealed and led to alternative ways to fill the void such as uncontrolled shopping [41]. One study highlighted that emotional stress, shame and self-contempt were strongly associated with experiences of regaining weight. Altered relations in the social world and control of health-related habits and practices were described [47]. Those who described themselves as successful attained previous expectations, but with some remaining concerns about future weight and aesthetics [46]. Those who described themselves as failures emphasized the expectation that surgery would change their lives [46]. The failure group lacked commitment and described healthy eating behaviour as a sacrifice [46].

\section{Discussion}

The aim of this review was to describe and systemize existing literature on patient-experiences in the context of obesity treatment. According to the inclusion criteria of the current review, only qualitative studies were read. The variety in the 15 included studies is naturally based on the difference in design and research focus. By including all types of obesity treatment, we revealed that the number of surgical interventions is much higher than any other treatment when it comes to studies of patients' own experiences in the area of obesity treatment. This may be a natural consequence of studies having shown the effect of surgery over several years [12]-[17]. We are surprised, however, that we found so few qualitative studies that discuss experiences after non-surgical treatment, such as lifestyle interventions, CBT or other behavioural or psychotherapeutic interventions. In addition, combined strategies in obesity treatment is lacking despite previous suggestions of combining, for instance, surgery and life style interventions [52]. This may be a result of the fact that research on bariatric surgery is very well documented and widely disseminated. However, it seems like the 
amount of qualitative designs targeting patients' perspectives is likely to be small in the field of obesity treatment research.

Emotional stress, shame and self-contempt play central roles in the management of weight and bodily issues after obesity treatment in this review. It appears that the search for positive self-existence after treatment is related not only to achieving weight balance but also to finding inner, positive self-existence and to gaining awareness of vulnerable feelings. Eating seems to be a way of managing emotional regulation as well as feelings of uncertainty about how to handle the new life and future. Self-blame and shame are triggered by a negative self-image, loss of hope or emptiness. This is in line with previous knowledges which document that shame plays a crucial role in obesity [21] [53] [54] and that regulating emotion may be significant in the maintenance of emotional eating and pathological overeating in obese persons with BED [55]. Our data reveals that the re-birth of a new body challenges the transformation of the self. A multiple explanation of failure leads to shifts between images of oneself and how they believe other people view themselves. According to Westermann et al. (2015) individuals with obesity respond with a specific increase in shame when faced with social exclusion [54]. The current review reveals that individuals wish to divulge their problems when they are emotionally vulnerable. At the same time, shame about the problems may lead to concealing problems. Different aspects, such as self-esteem and social relationships, are influenced by the weight loss.

The current review demonstrates huge differences in everyday life before and after weight loss. Expectations ahead of treatment seem to vary from being unreasonably sceptical to unreasonably optimistic. It is important to identify appropriate strategies for supporting people suffering from obesity to manage their new post-treatment life situation. The reasons for failure or success are multiple due to different treatment outcomes. The clinician's competence is important, as well as the grade and intensity of support achieved from the therapy. Being ambivalent as a patient when it comes to seeking or accepting treatment is typical. Types of supports in primary care or at the hospital setting are considered equally important when the patient wants to confront their obesity.

According to Meleis et al. (2000), the passage from the experience of suffering due to the life situation to the experience of health and wholeness is challenging. Our review highlights the importance of support after treatment and some may even need a long-term follow-up targeting the obesity treatment. Meleis et al. (2000) argue that supporting those undergoing transitions includes developing interventions that are valuable in helping regain stability and establish a meaningful life [27]. As described by Meleis et al. (2000), emotional processing seems to be an important element when facilitating transitions. According to our data, several conditions like lack of control and support may inhibit healthy transitions.

Ambivalence to the new foodstuffs and becoming eating-sensitive seem to be 
common. Surgical treatment appears to have an enormous impact on the persons' lives due to fast and heavy weight-loss and food complications. Some may even discover that food is an emotional regulator during and after treatment and from the findings in this review, such awareness may reveal self-blame and shame. This is in line with literature documenting how eating behaviours may be related to the balance of the emotional regulation system [56].

As revealed in this review, surgery may neglect the mind and a different focus on control may be revealed; food and bodily issues may be a manifestation of senses of control. It is explicit that those who undergo obesity surgery are in control over their weight and responsible for the post-surgical outcome [57]. The current review highlights that different aspects of treatment failure versus treatment success seem to entail a feeling of losing or gaining control. There is a balance between treatment failure and success as our review reports satisfaction with treatment despite unsuccessful weight-loss intervention (surgery). The need for help after weight-loss treatment is multifaceted and varies along a continuum of different needs for help, support and further therapy. If the treatment is a failure, the patients may begin to lose hope, which is in line with literature describing how the weight regain exacerbate hopelessness with regard to having a slim body and a normal life [57].

In our review, the post-treatment phase is described as an adaption process as the patients need to adapt to huge changes in food, lifestyle, weight, dressing and activities. We suggest that to alleviate suffering successfully and to facilitate adaptation, useful transition strategies are needed. Meleis (2000) proposes that the transition perspective be extended by including the experiences of additional patient groups such as persons suffering from obesity. The rapid transformation is current in the patient's mind, body and social self. In the search for positive self-existence after obesity treatment, new demands need to be handled in the daily life situation, and difficult changes may occur. As the bodily sensation changes, the mind may be confused. The ambivalent mind takes form and becomes emotionally stressed, ashamed and self-concerned as described in this review.

\subsection{Methodological Considerations}

We performed an interpretative analysis in our review; the themes intend to reflect different perspectives on the obesity treatment as experienced by the patients and as described in the included studies. This was performed in line with Dixon-Woods (2005), which highlights the importance of clarifying the reviews' aim, procedure and whether the analysis is descriptive or interpretative.

We are aware that the mixed-method design may highlight other aspects of patients' experiences of obesity treatment since it would provide knowledge based on a different epistemology and ontology [29]. Issues such as saturation, relationship between the researcher and participants, the researchers' role are not highlighted and will remain limited. According to critical criteria (CASP) 
detailed description of the selection strategies along with information about how and where the interviews were conducted should be appropriate for the aim of the review and an overview of the assessment of the included studies may be found in Appendix II. As our review focused on experiences of treatment we may have missed studies on the borderline between treatment and patient educational courses. Therefore, we might have excluded studies that would have contributed to a deeper knowledge in the research area.

\subsection{Implications for Further Research and Clinical Practice}

Future interventions should take into account that physical and mental treatment must work hand concurrently. It is crucial that clinicians be aware of the potential existential struggle experienced by the individual patients. As a result, some patients have more need of interventions targeting mental challenges than others.

This review provides important knowledge for nurses, clinicians and other healthcare workers in their education and training, as well as for the education of patients and their next-of-kin. We suggest that some of the aspects be implemented in a group treatment intervention.

A future study-protocol should pay attention to how patients experience treatment and different interventions when seeking obesity treatment both in the community care system and in hospital. More in-depth knowledge about experiences in the vulnerable transition is needed in this area in order to succeed in treatment.

\section{Conclusion}

The experiences among obese people after treatment are complex. Findings clearly indicate struggles on different levels and a need for strength to achieve a meaningful life after obesity treatment. The inner struggle should be detected to provide more successful treatment and follow-up during the transition process. It is crucial that the patients be supported in their quest for a meaningful life.

\section{References}

[1] Larrieu, S., et al. (2004) Relationship between Body Mass Index and Different Domains of Disability in Older Persons: The 3C Study. International Journal of Obesity and Related Metabolic Disorders, 28, 1555-1560. https://doi.org/10.1038/sj.ijo.0802755

[2] de Wit, L.M., et al. (2010) Depressive and Anxiety Disorders and the Association with Obesity, Physical, and Social Activities. Depress Anxiety, 27, 1057-1065. https://doi.org/10.1002/da.20738

[3] Gariepy, G., Nitka, D. and Schmitz, N. (2010) The Association between Obesity and Anxiety Disorders in the Population: A Systematic Review and Meta-Analysis. International Journal of Obesity (Lond), 34, 407-419. https://doi.org/10.1038/ijo.2009.252

[4] Anderson, S.E., et al. (2007) Adolescent Obesity and Risk for Subsequent Major 
Depressive Disorder and Anxiety Disorder: Prospective Evidence. Psychosomatic Medicine, 69, 740-747. https://doi.org/10.1097/PSY.0b013e31815580b4

[5] Jorm, A.F., et al. (2003) Association of Obesity with Anxiety, Depression and Emotional Well-Being: A Community Survey. Australian and New Zealand Journal of Public Health, 27, 434-440. https://doi.org/10.1111/j.1467-842X.2003.tb00423.x

[6] Luppino, F.S., et al. (2010) Overweight, Obesity, and Depression: A Systematic Review and Meta-Analysis of Longitudinal Studies. Archives of General Psychiatry, 67, 220-229. https://doi.org/10.1001/archgenpsychiatry.2010.2

[7] Andersen, J.R., et al. (2010) Anxiety and Depression in Association with Morbid Obesity: Changes with Improved Physical Health after Duodenal Switch. Health and Quality of Life Outcomes, 8, 52. https://doi.org/10.1186/1477-7525-8-52

[8] Wilson, G.T., Grilo, C.M. and Vitousek, K.M. (2007) Psychological Treatment of Eating Disorders. American Psychologist, 62, 199-216. https://doi.org/10.1037/0003-066X.62.3.199

[9] Ford, T.P., Lee, H.P. and Jeon, M.M. (2017) The Emotional Eating and Negative Food Relationship Experiences of Obese and Overweight Adults. Social Work in Health Care, 56, 488-504. https://doi.org/10.1080/00981389.2017.1301620

[10] Andersson, K., Shadloo, M. and Rudolfsson, G. (2016) Growing as a Human Being-Obese Adolescents' Experiences of the Changing Body. Journal of Pediatric Nursing, 31, e53-e62. https://doi.org/10.1016/j.pedn.2015.07.007

[11] Mold, F. and Forbes, A. (2013) Patients' and Professionals' Experiences and Perspectives of Obesity in Health-Care Settings: A Synthesis of Current Research. Health Expectations, 16, 119-142. https://doi.org/10.1111/j.1369-7625.2011.00699.x

[12] Hermreck, A.S., Jewell, W.R. and Hardin, C.A. (1976) Gastric Bypass for Morbid Obesity: Results and Complications. Surgery, 80, 498-505.

[13] Adams, T.D., et al. (2012) Health Benefits of Gastric Bypass Surgery after 6 Years. $J A M A$, 308, 1122-1131. https://doi.org/10.1001/2012.jama.11164

[14] Arterburn, D.E., et al. (2015) Association between Bariatric Surgery and Long-Term Survival. JAMA, 313, 62-70. https://doi.org/10.1001/jama.2014.16968

[15] Birn, I., et al. (2016) The Association Between Preoperative Symptoms of Obesity in Knee and Hip Joints and the Change in Quality of Life After Laparoscopic Roux-en-Y Gastric Bypass. Obesity Surgery, 26, 950-956.

https://doi.org/10.1007/s11695-015-1845-x

[16] Aasprang, A., et al. (2008) [Health-Related Quality of Life before and One Year after Operation for Morbid Obesity.] Tidsskr Nor Laegeforen, 128, 559-562.

[17] White, B., et al. (2015) Systematic Review of Psychological and Social Outcomes of Adolescents Undergoing Bariatric Surgery, and Predictors of Success. Clinical Obesity, 5, 312-24. https://doi.org/10.1111/cob.12119

[18] Ritz, P., et al. (2013) Early Prediction of Failure to Lose Weight after Obesity Surgery. Surgery for Obesity and Related Diseases, 9, 118-121. https://doi.org/10.1016/j.soard.2011.10.022

[19] Nelson, D.W., Blair, K.S. and Martin, M.J. (2012) Analysis of Obesity-Related Outcomes and Bariatric Failure Rates with the Duodenal Switch vs. Gastric Bypass for Morbid Obesity. Archives of Surgery, 147, 847-854.

https://doi.org/10.1001/archsurg.2012.1654

[20] Bordignon, S., et al. (2017) Personality Characteristics and Bariatric Surgery Outcomes: A Systematic Review. Trends in Psychiatry and Psychotherapy, 39, 124-134.

[21] Sjoberg, R.L., Nilsson, K.W. and Leppert, J. (2005) Obesity, Shame, and Depression 
in School-Aged Children: A Population-Based Study. Pediatrics, 116, e389-e392. https://doi.org/10.1542/peds.2005-0170

[22] Rand, K., et al. (2017) It Is Not the Diet; It Is the Mental Part We Need Help with. A Multilevel Analysis of Psychological, Emotional, and Social Well-Being in Obesity. International Journal of Qualitative Studies on Health and Well-Being, 12, Aritcle ID: 1306421. https://doi.org/10.1080/17482631.2017.1306421

[23] Larsen, J.K., et al. (2006) Binge Eating and Exercise Behavior after Surgery for Severe Obesity: A Structural Equation Model. International Journal of Eating Disorders, 39, 369-375. https://doi.org/10.1002/eat.20249

[24] Fairburn, C.G. and Harrison, P.J. (2003) Eating Disorders. The Lancet, 361, 407-416. https://doi.org/10.1016/S0140-6736(03)12378-1

[25] Herman, B.K., et al. (2014) The Patient Experience with DSM-5-Defined Binge Eating Disorder: Characteristics, Barriers to Treatment, and Implications for Primary Care Physicians. Postgraduate Medicine, 126, 52-63. https://doi.org/10.3810/pgm.2014.09.2800

[26] Wikstrand, I., Torgerson, J. and Bostrom, K.B. (2010) Very Low Calorie Diet (VLCD) Followed by a Randomized Trial of Corset Treatment for Obesity in Primary Care. Scandinavian Journal of Primary Health Care, 28, 89-94. https://doi.org/10.3109/02813431003778540

[27] Meleis, A.I., et al. (2000) Experiencing Transitions: An Emerging Middle-Range Theory. Advances in Nursing Science, 23, 12-28.

https://doi.org/10.1097/00012272-200009000-00006

[28] Polit, D.F. and Beck, C.T. (2004) Nursing Research: Principles and Methods. Lippincott Williams \& Wilkins, Philadelphia, Vol. 17, 758 s.

[29] Dixon-Woods, M., et al. (2005) Synthesising Qualitative and Quantitative Evidence: A Review of Possible Methods. Journal of Health Services Research \& Policy, 10, 45-53. https://doi.org/10.1177/135581960501000110

[30] Noyes, J. and Popay, J. (2007) Directly Observed Therapy and Tuberculosis: How Can a Systematic Review of Qualitative Research Contribute to Improving Services? A Qualitative Meta-Synthesis. Journal of Advanced Nursing, 57, 227-243. https://doi.org/10.1111/j.1365-2648.2006.04092.x

[31] Ring, N., et al. (2011) Understanding What Helps or Hinders Asthma Action Plan Use: A Systematic Review and Synthesis of the Qualitative Literature. Patient Education and Counseling, 85, e131-e143. https://doi.org/10.1016/j.pec.2011.01.025

[32] Hansen, B.S., et al. (2012) Patient Experiences of Uncertainty-A Synthesis to Guide Nursing Practice and Research. Journal of Nursing Management, 20, 266-277. https://doi.org/10.1111/j.1365-2834.2011.01369.x

[33] Polit, D.F. and Beck, C.T. (2014) Essentials of Nursing Research: Appraising Evidence for Nursing Practice. Wolters Kluwer/Lippincott Williams \& Wilkins, Philadelphia, Vol. 18, 493 s.

[34] Malterud, K. (2017) Kvalitativ metasyntese som forskningsmetode i medisin og helsefag. Universitetsforl, Oslo.

[35] Graneheim, U.H. and Lundman, B. (2004) Qualitative Content Analysis in Nursing Research: Concepts, Procedures and Measures to Achieve Trustworthiness. Nurse Education Today, 24, 105-112. https://doi.org/10.1016/j.nedt.2003.10.001

[36] CASP (2013) Critical Appraisal Skills Programme.

[37] Geraci, A.A., Brunt, A.R. and Marihart, C.L. (2014) Social Support Systems: A Qualitative Analysis of Female Bariatric Patients after the First Two Years Postoperative. 
Bariatric Surgical Practice and Patient Care, 9, 66-71. https://doi.org/10.1089/bari.2014.0004

[38] Natvik, E., et al. (2014) Re-Embodying Eating: Patients' Experiences 5 Years after Bariatric Surgery. Qualitative Health Research, 24, 1700-1710. https://doi.org/10.1177/1049732314548687

[39] Ogden, J., Avenell, S. and Ellis, G. (2011) Negotiating Control: Patients' Experiences of Unsuccessful Weight-Loss Surgery. Psychology \& Health, 26, 949-964. https://doi.org/10.1080/08870446.2010.514608

[40] Ostberg, A.L., Wikstrand, I. and Bengtsson Bostrom, K. (2011) Group Treatment of Obesity in Primary Care Practice: A Qualitative Study of Patients' Perspectives. Scandinavian Journal of Public Health, 39, 98-105. https://doi.org/10.1177/1403494810391524

[41] LePage, C.T. (2010) The Lived Experience of Individuals following Roux-en-Y Gastric Bypass Surgery: A Phenomenological Study. Bariatric Nursing and Surgical Patient Care, 5, 57-64. https://doi.org/10.1089/bar.2009.9938

[42] Malterud, K. and Ulriksen, K. (2010) Obesity in General Practice: A Focus Group Study on Patient Experiences. Scandinavian Journal of Primary Health Care, 28, 205-210. https://doi.org/10.3109/02813432.2010.526773

[43] Visram, S., Crosland, A. and Cording, H. (2009) Triggers for Weight Gain and Loss among Participants in a Primary Care-Based Intervention. British Journal of Community Nursing, 14, 495-501. https://doi.org/10.12968/bjcn.2009.14.11.45008

[44] Ogden, J., Clementi, C. and Aylwin, S. (2006) The Impact of Obesity Surgery and the Paradox of Control: A Qualitative Study. Psychology \& Health, 21, 273-293. https://doi.org/10.1080/14768320500129064

[45] Wiklund, M., Olbers, F.M. and Willén, C. (2014) Experiences of Physical Activity One Year after Bariatric Surgery. The Open Obesity Journal, 6, 25-30. https://doi.org/10.2174/1876823701406010025

[46] Da Silva, S.S. and Maia Ada, C. (2013) Patients' Experiences after Bariatric Surgery: A Qualitative Study at 12-Month Follow-Up. Clinical Obesity, 3, 185-193. https://doi.org/10.1111/cob.12032

[47] Natvik, E., Gjengedal, E. and Raheim, M. (2013) Totally Changed, Yet Still the Same: Patients' Lived Experiences 5 Years beyond Bariatric Surgery. Qualitative Health Research, 23, 1202-1214. https://doi.org/10.1177/1049732313501888

[48] Ogden, J. and Sidhu, S. (2006) Adherence, Behavior Change, and Visualization: A Qualitative Study of the Experiences of Taking an Obesity Medication. Journal of Psychosomatic Research, 61, 545-552. https://doi.org/10.1016/j.jpsychores.2006.04.017

[49] Psarou, A. and Brown, I. (2010) Patients' Experiences of Prescribed Anti-Obesity Drugs and Perceptions of Support from Primary Care: A Qualitative Study. Primary Health Care Research \& Development. Primary Health Care Research \& Development, 11, 250-259. https://doi.org/10.1017/S1463423610000083

[50] Drew, P. (2011) But Then I Learned ...: Weight Loss Surgery Patients Negotiate Surgery Discourses. Social Science \& Medicine, 73, 1230-1237. https://doi.org/10.1016/j.socscimed.2011.07.023

[51] Klassen, A.F., et al. (2012) Satisfaction and Quality-of-Life Issues in Body Contouring Surgery Patients: A Qualitative Study. Obesity Surgery, 22, 1527-1534. https://doi.org/10.1007/s11695-012-0640-1

[52] Johnson, L.K., et al. (2013) Dietary Changes in Obese Patients Undergoing Gastric 
Bypass or Lifestyle Intervention: A Clinical Trial. British Journal of Nutrition, 110, 127-134. https://doi.org/10.1017/S0007114512004631

[53] Lier, H.O., et al. (2013) Prevalence of Psychiatric Disorders before and 1 Year after Bariatric Surgery: The Role of Shame in Maintenance of Psychiatric Disorders in Patients Undergoing Bariatric Surgery. Nordic Journal of Psychiatry, 67, 89-96. https://doi.org/10.3109/08039488.2012.684703

[54] Westermann, S., et al. (2015) Social Exclusion and Shame in Obesity. Eating Behaviors, 17, 74-76. https://doi.org/10.1016/j.eatbeh.2015.01.001

[55] Gianini, L.M., White, M.A. and Masheb, R.M. (2013) Eating Pathology, Emotion Regulation, and Emotional Overeating in Obese Adults with Binge Eating Disorder. Eating Behaviors, 14, 309-313. https://doi.org/10.1016/j.eatbeh.2013.05.008

[56] Micanti, F., et al. (2017) The Relationship between Emotional Regulation and Eating Behaviour: A Multidimensional Analysis of Obesity Psychopathology. Eating and Weight Disorders, 22, 105-115. https://doi.org/10.1007/s40519-016-0275-7

[57] Groven, K.S. and Glenn, N.M. (2016) The Experience of Regaining Weight Following Weight Loss Surgery: A Narrative-Phenomenological Exploration. Health Care for Women International, 37, 1185-1202.

https://doi.org/10.1080/07399332.2016.1195386 


\section{Appendix I}

PRISMA 2009 flow diagram.

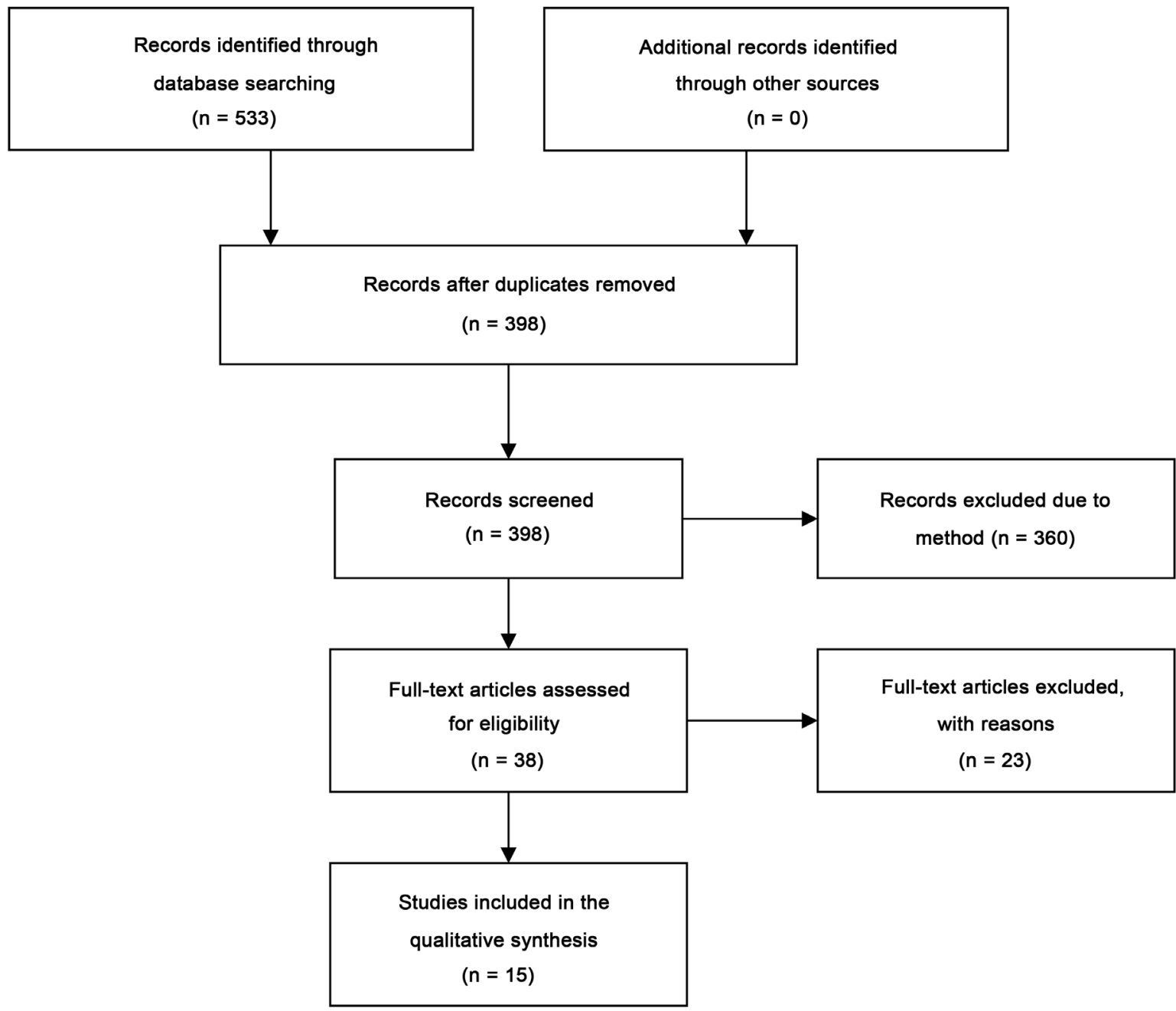

\section{Appendix II}

Results of quality assessment of the included studies based on the The Critical Appraisal Skills Program-checklist for qualitative studies (CASP 2013).

Questions in The Critical Appraisal Skills Program [36], a methodological checklist of key criteria relevant to qualitative studies

\begin{tabular}{|c|c|c|c|c|c|}
\hline $\begin{array}{l}\text { Yes/no/ } \\
\text { unclear }\end{array}$ & $\begin{array}{l}\text { 1. Was there a clear } \\
\text { statement of the aims } \\
\text { of the research? }\end{array}$ & $\begin{array}{l}\text { 2. Is a qualitative } \\
\text { methodology } \\
\text { appropriate? }\end{array}$ & $\begin{array}{l}\text { 3. Was the research } \\
\text { design appropriate to } \\
\text { address the aims } \\
\text { of the research }\end{array}$ & $\begin{array}{l}\text { 4. Was the recruitment } \\
\text { strategy appropriate } \\
\text { to the aims of } \\
\text { the research? }\end{array}$ & $\begin{array}{l}\text { 5. Were the data } \\
\text { collected in a way } \\
\text { that addressed the } \\
\text { research issue? }\end{array}$ \\
\hline $\begin{array}{l}\text { Yes/no/ } \\
\text { unclear }\end{array}$ & $\begin{array}{l}\text { 6. Has the relationship } \\
\text { between researcher } \\
\text { and participants } \\
\text { been adequately } \\
\text { considered? }\end{array}$ & $\begin{array}{l}\text { 7. Have ethical } \\
\text { issues been taken } \\
\text { into consideration? }\end{array}$ & $\begin{array}{l}\text { 8. Was the data analysis } \\
\text { sufficiently rigorous? }\end{array}$ & $\begin{array}{l}\text { 9. Is there a clear } \\
\text { statement of findings? }\end{array}$ & $\begin{array}{l}\text { 10. How valuable } \\
\text { is the research? }\end{array}$ \\
\hline
\end{tabular}


K. Rørtveit et al.

\begin{tabular}{|c|c|c|c|c|c|c|c|c|c|c|c|}
\hline & First author, year/CASP-questions & 1 & 2 & 3 & 4 & 5 & 6 & 7 & 8 & 9 & 10 \\
\hline 1 & Geraci 2014 & y & $\mathrm{y}$ & $\mathrm{y}$ & y & $\mathrm{y}$ & $\mathrm{u}$ & $\mathrm{n}$ & $\mathrm{y}$ & y & $\mathrm{h}$ \\
\hline 2 & Natvig 2014 & $\mathrm{y}$ & $\mathrm{y}$ & $\mathrm{y}$ & $\mathrm{y}$ & $\mathrm{y}$ & $\mathrm{y}$ & $\mathrm{y}$ & $\mathrm{y}$ & y & $\mathrm{h}$ \\
\hline 3 & Wiklund 2014 & $\mathrm{y}$ & $\mathrm{y}$ & $\mathrm{y}$ & $\mathrm{y}$ & y & $\mathrm{n}$ & $\mathrm{y}$ & $\mathrm{y}$ & $\mathrm{y}$ & $\mathrm{h}$ \\
\hline 4 & Da Silva 2013 & y & $\mathrm{y}$ & $\mathrm{y}$ & $\mathrm{y}$ & $\mathrm{y}$ & $\mathrm{n}$ & $\mathrm{y}$ & $\mathrm{y}$ & $\mathrm{y}$ & $\mathrm{h}$ \\
\hline 5 & Natvig 2013 & $\mathrm{y}$ & $\mathrm{y}$ & $\mathrm{y}$ & $\mathrm{y}$ & $\mathrm{y}$ & $\mathrm{y}$ & $\mathrm{y}$ & $\mathrm{y}$ & $\mathrm{y}$ & $\mathrm{h}$ \\
\hline 6 & Klassen 2012 & y & $\mathrm{y}$ & $\mathrm{y}$ & $\mathrm{y}$ & $\mathrm{y}$ & $\mathrm{n}$ & $\mathrm{y}$ & $\mathrm{u}$ & $\mathrm{y}$ & $\mathrm{h}$ \\
\hline 7 & Drew 2011 & $\mathrm{n}$ & $\mathrm{y}$ & $\mathrm{y}$ & $\mathrm{y}$ & $\mathrm{y}$ & $\mathrm{y}$ & $\mathrm{n}$ & $\mathrm{n}$ & $\mathrm{y}$ & $\mathrm{m}$ \\
\hline 8 & Ogden 2011 & $\mathrm{y}$ & $\mathrm{y}$ & $\mathrm{y}$ & $\mathrm{y}$ & $\mathrm{y}$ & $\mathrm{n}$ & $\mathrm{y}$ & $\mathrm{y}$ & $\mathrm{y}$ & $\mathrm{h}$ \\
\hline 9 & Ôstberg 2011 & $\mathrm{y}$ & $\mathrm{y}$ & $\mathrm{y}$ & $\mathrm{y}$ & $\mathrm{y}$ & $\mathrm{y}$ & $\mathrm{y}$ & $\mathrm{y}$ & $\mathrm{y}$ & $\mathrm{h}$ \\
\hline 10 & Psarou 2010 & $\mathrm{y}$ & $\mathrm{y}$ & $\mathrm{y}$ & $\mathrm{y}$ & $\mathrm{y}$ & $\mathrm{n}$ & $\mathrm{u}$ & $\mathrm{u}$ & $\mathrm{y}$ & $\mathrm{m}$ \\
\hline 11 & Le Page 2010 & y & $\mathrm{y}$ & $\mathrm{y}$ & $\mathrm{y}$ & $\mathrm{y}$ & $\mathrm{n}$ & $\mathrm{y}$ & $\mathrm{y}$ & $\mathrm{y}$ & $\mathrm{h}$ \\
\hline 12 & Malterud 2010 & $\mathrm{y}$ & $\mathrm{y}$ & $\mathrm{y}$ & $\mathrm{y}$ & $\mathrm{y}$ & $\mathrm{n}$ & $\mathrm{y}$ & $\mathrm{y}$ & $\mathrm{y}$ & $\mathrm{h}$ \\
\hline 13 & Visram 2009 & $\mathrm{y}$ & $\mathrm{y}$ & $\mathrm{y}$ & $\mathrm{y}$ & $\mathrm{y}$ & $\mathrm{n}$ & $\mathrm{u}$ & $\mathrm{y}$ & $\mathrm{y}$ & $\mathrm{h}$ \\
\hline 14 & Ogden 2006 & $\mathrm{y}$ & $\mathrm{y}$ & $\mathrm{y}$ & $\mathrm{y}$ & $\mathrm{y}$ & $\mathrm{n}$ & $\mathrm{y}$ & $\mathrm{y}$ & $\mathrm{y}$ & $\mathrm{h}$ \\
\hline 15 & Ogden 2006 & & & & & & & & & & \\
\hline
\end{tabular}

(y: yes, n: no, u: unclear, h: high, m: middle). 